\title{
A Study on the Team Effectiveness Construction of the Research Team the Moderating Effect of Share Mental Model
}

\author{
Xiao Dingding ${ }^{1, a}$, Tian Wenhua ${ }^{2, b}$ and Zhu Fei ${ }^{3^{*}, \mathrm{c}}$ \\ ${ }^{1}$ School of Management Science \& Engineering, Shandong Normal University, Jinan , China; \\ ${ }^{3}$ School of Management Science \& Engineering, Shandong Normal University, Jinan, China; \\ ${ }^{2}$ Yancheng Institute of Industry Technology, Yancheng, China; \\ axiaodingboy@163.com, b2570367763@qq.com, cmatte_19861115@163.com
}

\begin{abstract}
Keywords: Team Process; Team Effectiveness; Share Mental Model; Similarity; Accuracy
Abstract. The research explores the impact of team process (Behavioral Process and Emergent States) on the team effectiveness with share mental model (SMM) as a moderating variable. The results show that: task conflict has a significantly positive impact on team effectiveness, while relationship conflict shows the opposite effect; both team heterogeneity and formalization have significantly positive impact on team effectiveness; the SMM quality has a significantly moderating effect on team process and effectiveness, while SMM similarity moderates the relationship between team heterogeneity and effectiveness, and SMM accuracy moderates the relationship between task conflict and team effectiveness. Finally, the empirical results, the management implication.
\end{abstract}

\section{Introduction}

With the advent of the era of "big science", the scientific research team gradually tends to become the backbone force to develop frontier areas, promote interdisciplinary integration of subjects and undertake major projects. For example, the National Natural Science Foundation has invested more than 3.4 billion to finance 379 groups of innovative research since 2000, so as to promote the advanced research of basic subjects. However, the state of research team cooperation is not optimistic in reality, such as "free rider", breach of contract, and other acts of interest conflict in the team[1]. Therefore, how to enhance the satisfaction degree of team members and cooperative performance level, has become a topic of common concern among scholars and managers both domestic and abroad [2, 3].

Aiming at the problem of team effectiveness, from the research perspective, studies focus on the effects of team process variables between team input and team effectiveness[2]. However, those will not explain the impact mechanism between the team process and team effectiveness from a cognitive perspective; From the point of research object, scholars mainly regarded virtual teams, the work team, as well as the senior management team as the object of study[3], few scholars carried out empirical analysis on the university scientific research team ,however, university research team has particularity in social function, organization forms and the distribution of benefits[1]. These particularity lead to differences between team process variable connotation and the mechanism influencing team effectiveness. Aiming at the shortage of the research perspective and content, this paper tries to discuss the relationship between the team process, team effectiveness and the Share mental model, and combine with the empirical results to put forward the optimization suggestion .

\section{Theoretical Foundation and Hypothesis Development}

The Team effectiveness and Connotation of Team process

Team effectiveness should include personal, team and the business unit and other levels, and also pay attention to the interaction between team(performance, ability) and individual(attitude, behavior) in two dimensions. with the consideration of the characteristics of university scientific research

*Corresponding author. 
team[1]. This article follows the division of dimensions of team effectiveness of Heckman:(1)the performance of the team; (2)member satisfaction degree; (3)the growth of the team [2].

The team process shows the interactive relationship between members and external. with the consideration of the operation characteristics of university scientific research team, according to Pelled's induction, the team process is divided into Behavioral Process and Emergent States [4]. The behavior process focuses on task conflict and relationship conflict; the state of team includes team heterogeneity and team formalization[4].

\section{The Relationship between Team Process and Team Effectiveness}

Team conflict exists in team members, as well as members and team, due to the process caused by target, concept, sense of worth, interests and other opposition or disagreement. Relationship conflict stems from the differences of sense of worth or personality among members, when relationship conflict occurs, team members no longer work in harmony and undermine the efficiency of joint decision-making of team[5]; however, task conflict can guide in-depth discussions among the different views of team members and contribute to reflection, communication and eliminate doubt, so as to enable the team to have more creative energy[6]. Based on the analysis above, we propose the following hypothesis:

H1a: In the university research team, the task conflict has a significant positive impact on team effectiveness;

H1b: In the university research team, the relationship conflict has a significant negative impact on team effectiveness;

Team heterogeneity and formalization have become the key state variables to maintain the common goal of the team[5]. It has been found that university research team focused on "mentor + student" mode with edge-based academic team, the strong homogeneous of members inhibits team creativity. on the other hand, Team heterogeneity contribute to reviewing the team from different angles, then form a better solution scheme[7]. Especially under the "big science" background, tackling major scientific research projects requires not only team members with complementary knowledge of heterogeneous structure, but also more formalized management and coordination mechanism of members to avoid relationship conflict in decision-making and collaboration. Based on the analysis above, we propose the following hypothesis:

H2a: In the university research team, team heterogeneity has a significant positive effect on team effectiveness;

$\mathrm{H} 2 \mathrm{~b}$ : In the scientific research team, team formalization has a significant positive impact on team effectiveness;

\section{Effect of Shared Mental Model on Team Processes and Team Effectiveness Relationship}

It is the share mental model that is the internal psychological mechanism that members rely on carrying on problem representation and information coding[4]. Domestic and foreign scholars separately carried on tests on the role mechanisms of team and task-based mental model and team creativity, organizational knowledge management, however, it is obvious that the empirical research aiming at similarity and accuracy of the share mental model and team effectiveness is lacked.

Share mental model similarity refers to team members' similar pattern of recognition and response in the same event[8]. Edwards etc. showed that highly similar mental models make members focus on a specific research field, at the same time of maximizing the use of members' knowledge heterogeneity, improving the team performance and overall cohesion; meanwhile mental model consistency promotes the group thinking which is conducive to the construction of standardized management system and solutions[9]. Based on the analysis above, we propose the following hypothesis:

H3a:Team mental model consistency has a significant moderating effect on the relationship between team heterogeneity and team effectiveness; 
$\mathrm{H} 3 \mathrm{~b}$ :Team mental model consistency has a significant moderating effect on team formalization and team effectiveness;

Shared mental model accuracy refers to accuracy degree of members' analysis and interpretation of events as well as its environment [8]. Lv Xiaojun has found that the relationship between the indexes of the mental model and team efficacy is entirely effected by the team conflict, cooperation and other factors[10]. However, Acton etc. found that accuracy of team mental models lead to team efficiency gradually declining, the accuracy of team mental models increases continuously as time goes on, it plays a partial mediating role between team competence and performance. Based on the analysis above, this paper puts forward to the following assumptions:

H4a: The accuracy of team mental model has a significant moderating effect on the relationship between task conflict and team efficiency;

H4b: The accuracy of team mental model has a significant moderating effect on relationship conflict and team effectiveness;

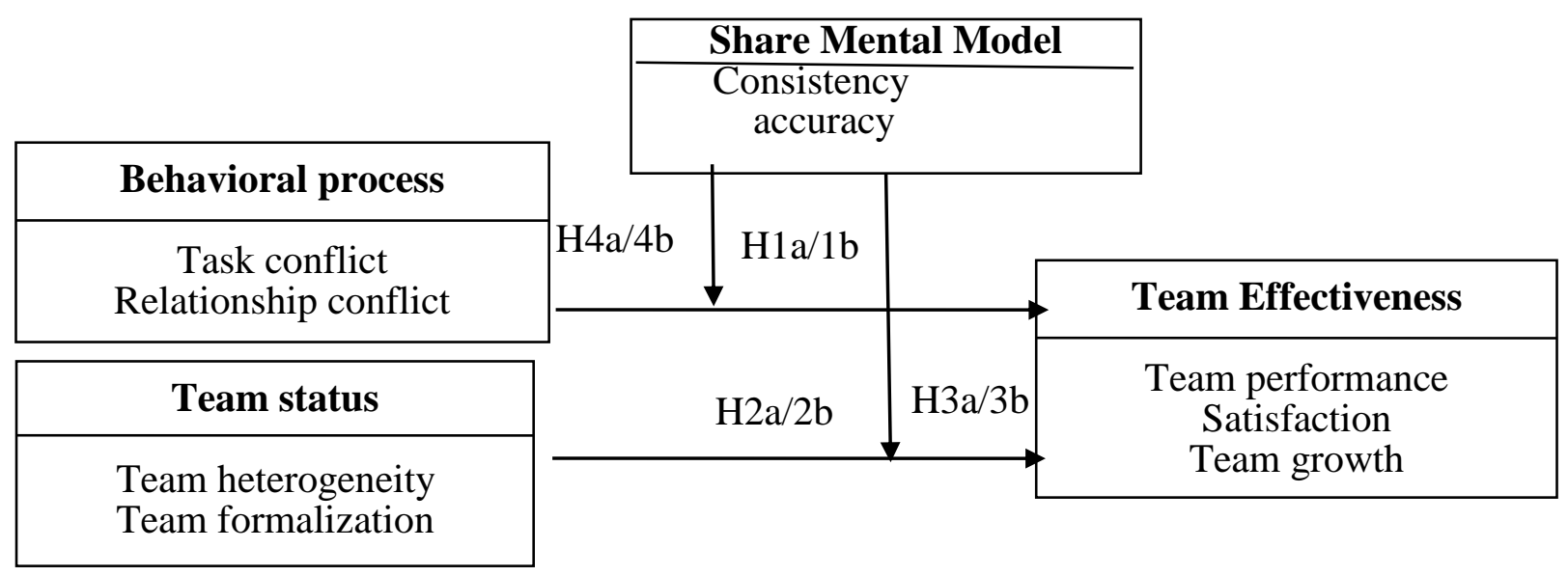

\section{Research Design}

Fig.1. Theoretical Model

Based on the survey data of 101 research teams in the South China, 500 sets of questionnaires were issued by e-mail, and 164 sets were received, 101 valid questionnaires were identified, and the effective recovery rate was $20.2 \%$.

Team Effectiveness includes three indicators: team performance, team member satisfaction and growth[2]. Team process includes four variables: task conflict, relationship conflict, heterogeneity and formalization[5]. The consistency and accuracy of measurement according to the research of Lv Xiaojun[10], for convenient measurement, the consistency and accuracy scale were converted to Likert scale.

\section{Research results}

\section{descriptive statistics}

In this paper, SPSS16.0 is used to analyze the data of each variable.

Table 1 descriptive statistics of variable and correlation coefficient

\begin{tabular}{|c|c|c|c|c|c|c|c|c|c|}
\hline variable & mean & $\begin{array}{l}\text { standard } \\
\text { deviation }\end{array}$ & 1 & 2 & 3 & 4 & 5 & 6 & 7 \\
\hline 1.Task conflict & 3.073 & 0.643 & 1 & & & & & & \\
\hline 2.Relationship conflict & 2.656 & 0.729 & 0.347 & 1 & & & & & \\
\hline 3.Team heterogeneity & 2.382 & 0.643 & 0.233 & 0.284 & 1 & & & & \\
\hline 4.Team formalization & 2.171 & 0.628 & 0.191 & 0.392 & 0.148 & 1 & & & \\
\hline 5.Consistency & 2.771 & 0.774 & 0.352 & 0.376 & 0.313 & 0.326 & 1 & & \\
\hline 6.Accuracy & 2.028 & 0.639 & 0.262 & 0.221 & 0.280 & 0.204 & 0.117 & 1 & \\
\hline 7.Team effectiveness & 3.872 & 0.509 & 0.238 & -0.152 & 0.314 & 0.274 & 0.352 & 0.218 & 1 \\
\hline
\end{tabular}

Note: correlation coefficients were all passed by significance test $(\mathrm{P}<0.001)$. 


\section{Hypothesis Testing}

The purpose of this paper is to test the direct influence of team status and behavioral process on team effectiveness, and to test moderating effect of shared mental model's consistency and validity between the two. This paper use hierarchical regression method for statistical analysis.

Table 2 summary sheet of the results of hierarchical regression analysis

\begin{tabular}{|c|c|c|c|c|c|c|}
\hline \multirow[t]{2}{*}{ Dependent variable } & \multicolumn{6}{|c|}{ Team Effectiveness } \\
\hline & Model 1 & Model 2 & $\begin{array}{c}\text { Model } \\
3-1\end{array}$ & $\begin{array}{l}\text { Model } \\
3-2\end{array}$ & $\begin{array}{c}\text { Model } \\
4-1\end{array}$ & $\begin{array}{l}\text { Model } \\
4-2\end{array}$ \\
\hline Constant term & $2.89^{* * *}$ & $2.796^{* * *}$ & $2.714^{* * * *}$ & $2.313^{* * * *}$ & $2.245^{* * *}$ & $2.313^{* *}$ \\
\hline \multicolumn{7}{|l|}{ control variable } \\
\hline Team size & -0.102 & -0.11 & -0.124 & -0.133 & -0.088 & -0.113 \\
\hline Team age & $0.15^{* * *}$ & $0.178^{* * *}$ & $0.184^{* * *}$ & $0.159^{* * *}$ & $0.108^{* * *}$ & $0.175^{* * *}$ \\
\hline Laboratory level & $0.053^{* * *}$ & $0.064^{* * * *}$ & $0.07^{* * *}$ & $0.068^{* * *}$ & $0.094^{* * *}$ & $0.056^{* * *}$ \\
\hline \multicolumn{7}{|l|}{ independent variable } \\
\hline Task conflict & & $0.279^{* * *}$ & $0.247^{* * *}$ & $0.282^{* * *}$ & $0.184^{* * *}$ & $0.202^{* * *}$ \\
\hline Relationship conflict & & $-0.022^{* *}$ & $-0.034^{* *}$ & $-0.026^{* *}$ & $-0.047^{* *}$ & $-0.056^{* *}$ \\
\hline Team heterogeneity & & $0.157^{*}$ & $0.147^{*}$ & $0.116^{*}$ & $0.137^{*}$ & $0.105^{*}$ \\
\hline Team formalization & & $0.141^{* *}$ & $0.129^{* *}$ & $0.135^{* *}$ & $0.142^{* *}$ & $0.135^{* *}$ \\
\hline \multicolumn{7}{|l|}{ Adiustment variable } \\
\hline Consistency & & & $0.297^{* *}$ & $0.31^{* *}$ & & \\
\hline Accuracy & & & & & $0.245^{* * *}$ & $0.331^{* * *}$ \\
\hline \multicolumn{7}{|l|}{ Cross term } \\
\hline $\begin{array}{l}\text { ConsistencyxTeam } \\
\text { heterogeneity }\end{array}$ & & & & $0.186^{* *}$ & & \\
\hline $\begin{array}{l}\text { Consistency } \times \text { Team } \\
\text { formalization }\end{array}$ & & & & 0.067 & & \\
\hline $\begin{array}{c}\text { Accuracy } \times \text { Task } \\
\text { conflict }\end{array}$ & & & & & & $0.143^{* *}$ \\
\hline $\begin{array}{l}\text { Accuracy } \times \text { Relationshi } \\
\text { p conflict }\end{array}$ & & & & & & -0.056 \\
\hline $\mathrm{R}^{2}$ & 0.071 & 0.525 & 0.542 & 0.605 & 0.538 & 0.588 \\
\hline$\triangle \mathrm{R}^{2}$ & -- & 0.454 & 0.017 & 0.063 & 0.013 & 0.050 \\
\hline Adjusted $\mathrm{R}^{2}$ & 0.069 & 0.511 & 0.528 & 0.591 & 0.520 & 0.573 \\
\hline $\mathrm{F}$ & $10.448^{* *}$ & $115.732^{*}$ & $16.373^{* *}$ & $28.507^{* * *}$ & $\underset{*}{17.535^{* *}}$ & $32.841^{* * *}$ \\
\hline
\end{tabular}

Note: ***Significant at 0.001 level, **Significant at 0.01 level, *Significant at 0.05 level

According to model 1, team's age and laboratory level in control variables have significant effect on team effectiveness $(\mathrm{P}<0.001)$, which indicates that with the deepening of interaction among members, the team leader has accumulated a wealth of management experience. Therefore, the ability of the team as a whole to deal with daily or emergencies is on the rise. The model 2 shows that the team process variables have significant effects on team effectiveness. In behavioral process variables, the regression coefficient of task conflict was $0.279(\mathrm{P}<0.001)$, it shows that task conflict has a significant positive effect on team effectiveness, and the regression coefficient of conflict was $-0.022(\mathrm{P}<0.01)$, indicating that the relationship conflict has a significant negative impact on team effectiveness, which supports the hypothesis $\mathrm{H} 1 \mathrm{a}$ and $\mathrm{H} 1 \mathrm{~b}$ respectively; in team state variables, the regression coefficient of team heterogeneity and formal are $0.157(\mathrm{P}<0.05)$ and $0.141(\mathrm{P}<0.01)$ respectively, indicating that both of them have a significant positive impact on team effectiveness, which supports the hypothesis $\mathrm{H} 2 \mathrm{a}$ and $\mathrm{H} 2 \mathrm{~b}$ respectively.

The 3-1,3-2 model shows that when the consistency and the product term of the team state variable are added to the regression equation, the regression coefficient of team heterogeneity and consistency cross term is $0.186(\mathrm{P}<0.01)$, indicating that the consistency has a significant 
moderating effect on the relationship between team heterogeneity and team effectiveness, which supports the hypothesis H3a. However, the moderating effect of consistency on team formalization and team effectiveness failed to pass the significant test $(\mathrm{P}>0.05)$, which does not support the hypothesis H3b. Similarly, the 4-1,4-2 model indicates that when the accuracy and the product term of the behavior process variable are added to the regression equation. The regression coefficient of task conflict and accuracy of cross terms is $0.143(\mathrm{P}<0.01)$, indicating that the accuracy has a significant moderating effect on the relationship between task conflict and team effectiveness, while hypothesis H4a has gained certificate; and the accuracy has failed to pass the significance test of moderating effects to relationship conflict and team effectiveness $(\mathrm{P}>0.05)$, which do not support the hypothesis $\mathrm{H} 4 \mathrm{~b}$.

\section{Conditioning Effect}

To describe the moderating effect of shared mental model about consistency and accuracy of the relationship between team process and team effectiveness, the paper makes moderating effect diagram. The Fig. 2,3 shows that the consistency and accuracy has a significant moderating effect on the relationship among team heterogeneity, task conflict and team effectiveness. When the consistency (or accuracy) is high, team heterogeneity (or task conflict) has more significant effect on team effectiveness .

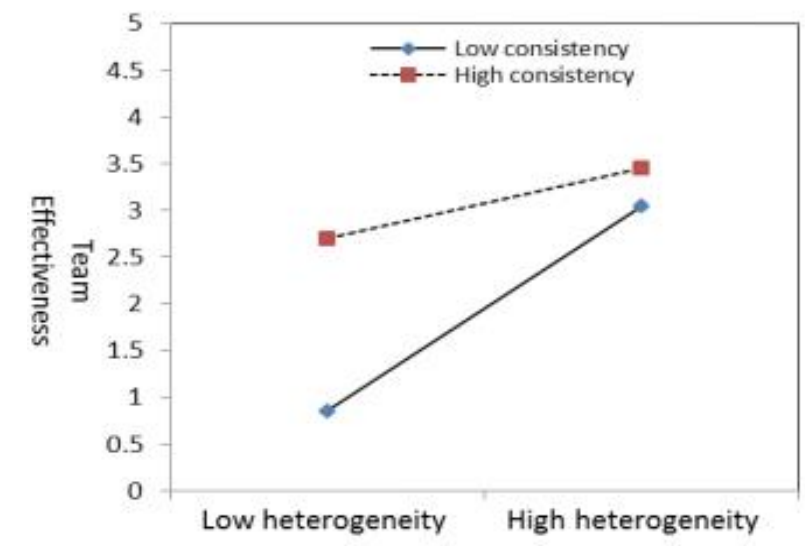

Fig. 2 The consistency of moderating effects

$\mathfrak{s}$ on team heterogeneity and team effectiveness

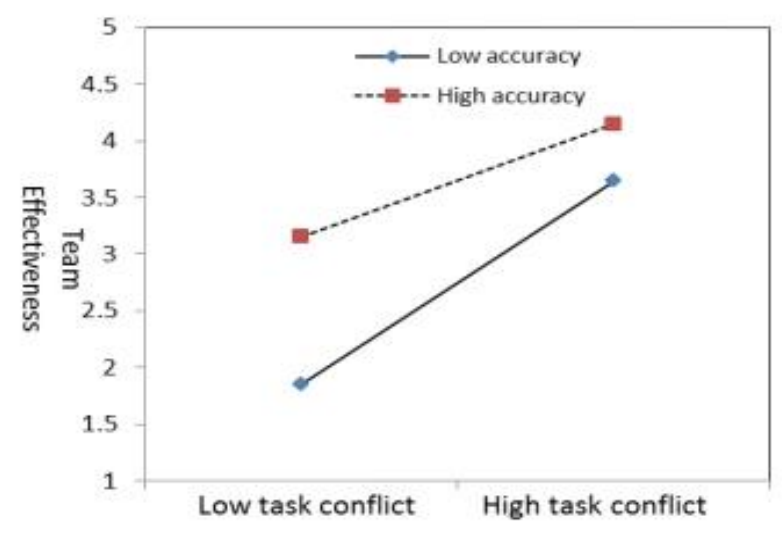

Fig.3 The accuracy of moderating effects on the relationship between task conflict and team effectiveness

\section{Conclusions of the Study}

This paper takes the consistency and accuracy of shared mental model as moderating variables, and discusses the influencing relationship between team process(the state and the behavior process of a team). The results show that, in the university research team, team process (team status and behavioral processes) have significant and direct impact on team effectiveness, while the consistency of shared mental model has a significant moderating effect on the relationship between team heterogeneity and team effectiveness, and accuracy has a significant moderating effect on the relationship between task conflict and team effectiveness.

First of all, this paper extends the connotation of team process variables and the research object. adding team state variables verified team process that has direct impact on the team effectiveness, and the priority of academic competition, members of academic structure internalize the connotation in the survey of university scientific research team conflict, team heterogeneity and other factors. It indicates that through the empirical test, the team heterogeneity, formalized, conflict has significant factors to team effectiveness.

Secondly, the previous scholars were lacked in research on the moderating effect of shared mental model and its quality to the team construction process. It has found that the consistency of shared mental model has a significant moderating effect on the relationship between team heterogeneity and team effectiveness, and the accuracy task has a significant moderating effect on 
the relationship between team conflict and team effectiveness relationship. And when the consistency and accuracy is in a high level, the team process can produce higher team effectiveness, but when the mental model is low, team process has more significant influence on team effectiveness (figure showed a greater slope of the line). The conclusion of the study reflects the importance of the interaction of two dimensions of knowledge and practice in the team construction, knowledge dimensions determine whether the team behavior that show internal collaboration, communication can transform into the cognitive mode of accurate, coordination; row dimension determines the ability of team members whether heterogeneous knowledge structure, flexible management model can be applied to team creativity, cohesion and other acts of members .

Finally, the enlightenment of the study is: (1) the research team's conflict of interest comes from the academic priority competition of knowledge innovation, how to coordinate knowledge sharing in the internal and external of a team and academic interest distribution is the key to enhancing the effectiveness of team ;(2) based on the stage of interdisciplinary background, we should keep team members knowledge, learn edge and cognitive structure heterogeneity; (3) paying attention to the unity of knowledge and practice, cognitive structure can be optimized through collaboration, conflict and other behavioral processes; the recognition model of consistent, accurate feedback to team building process, promoting the coordination between the members of mission planning.

\section{Acknowledgements}

This work was supported in part by the Key Fund of National Natural Science Foundation of China (71233003) and Youth Fund of National Natural Science Foundation of China (71403153) and the Major Fund of Philosophy and Social Science of the Ministry of Education (12JZD042).

\section{References}

[1]Xia Li. The Dilemma of Cooperation in Scientific Research of China[J].Science \& Technology Review , 2012, 30(13): 81.

[2]Hackman R H. The design of work team [J]. Handbook of Organizational Behavior, 1987:315-342.

[3]Mathieu J E, Heffner T S, Goodwin G F, et al. Scaling the quality of teammates' mental models: equifinality and normative comparisons [J]. Journal of Organizational Behavior, 2005, 26(1): 37-56.

[4]Pelled L H, Eisenhardt K M, Xin K R. Exploring the Black Box: An Analysis of Work Group Diversity, Conflict, and Performance [J].Administrative Science Quarterly, 1999, 44(1):1-28.

[5]Jehn K A, Mannix E A. The Dynamic Nature of Conflict: A Longitudinal Study of Intragroup Conflict and Group Performance [J]. Academy of Management Journal, 2001, 44(2): 238-251.

[6]De Dreu. When too little or too much hurts: Evidence for a curvilinear relationship between task conflict and innovation in teams [J]. Journal of Management, 2006, 32(1):83-107.

[7]Liu Ning,Jia Jun-Sheng.An Empirical Study on Team Diversity, Knowledge Sharing and Innovation Performance in R\&D Teams[J].Nankai Business Review,2012,15(6):85-92.

[8]Webber S S, Chen G, Payne S C, et al. Enhancing Team Mental Model Measurement with Performance Appraisal Practices [J]. Organizational Research Methods, 2000, 3(4):307-322.

[9]Edwards B D, Day E A, Arthur W J, et al. Relationships among Team Ability Composition, Team Mental Models, and Team Performance [J]. Journal of Applied Psychology. 2006, 91(3): 727-736.

[10]Lv Xiao-Jun.The Effects of Team Mental Models on Team Process and Team Effectiveness[J].Journal of psychological Science,2009, 32(2):440-442. 